OPEN ACCESS

Edited by:

Peter Dovc,

University of Ljubljana, Slovenia

Reviewed by:

Shahin Eghbalsaied,

Islamic Azad University Isfahan

Branch, Iran

Fabyano Fonseca Silva,

Universidade Federal de Viçosa, Brazil

*Correspondence:

Hasan Khatib

hkhatib@wisc.edu

Specialty section:

This article was submitted to

Livestock Genomics,

a section of the journal

Frontiers in Genetics

Received: 19 December 2016 Accepted: 20 March 2017

Published: 04 April 2017

Citation:

Gross N, Kropp J and Khatib H (2017) Sexual Dimorphism of miRNAs Secreted by Bovine In vitro-produced

Embryos. Front. Genet. 8:39.

doi: 10.3389/fgene.2017.00039

\section{Sexual Dimorphism of miRNAs Secreted by Bovine In vitro-produced Embryos}

\author{
Nicole Gross, Jenna Kropp and Hasan Khatib* \\ Department of Animal Sciences, University of Wisconsin, Madison, WI, USA
}

Sexual dimorphism of bovine blastocysts has previously been observed through differences in development, cell death, metabolism, telomere length, DNA methylation, and transcriptomics. However, dimorphism in the secretion of miRNAs to culture media has not yet been evaluated. The objectives of this study were to determine if sex-specific blastocyst miRNA secretion occurs and to further investigate the role these miRNAs may have in the interaction between a blastocyst and the maternal environment. In vitro embryo culture was performed and media from male and female blastocysts was collected into sex-specific pools. Profiling of 68 miRNAs revealed a total of eight miRNAs that were differentially expressed between female and male-conditioned media. Validation by qPCR confirmed higher expression of miR-22 $(P<0.05)$, miR-122 $(P<0.05)$, and miR-320a $(P<0.05)$ in female media for three additional biological replicates. To examine the potential roles of secreted miRNAs to the media in communication with the maternal environment, miR-22, miR-122, and miR-320a were each supplemented to four replicates of primary bovine endometrial epithelial cell culture. Uptake of miR-122 $(P<0.05)$ and miR-320a $(P<0.05)$ was detected, and a trend of uptake was detected for miR-22 $(P>0.05)$. Further, expression of the progesterone receptor transcript, a predicted target of all three miRNAs, was found to be upregulated in the cells following supplementation of miR-122 $(P<0.05)$ and miR-320a $(P<0.05)$, and a trend upregulation of the transcript was observed following miR-22 $(P>0.05)$ supplementation. This work demonstrates that male and female conceptuses are able to differentially secrete miRNAs at the blastocyst stage and that these miRNAs have the ability to induce a transcriptomic response when applied to maternal cells. This knowledge builds on the known dimorphic differences in conceptuses at the blastocyst stage and demonstrates a role for blastocyst-secreted miRNAs in cell-cell communication.

Keywords: microRNA, sexual dimorphism, embryo, culture media, bovine

\section{INTRODUCTION}

Mammalian embryos exhibit sexual dimorphism in development, genetics, and epigenetics (Laguna-Barraza et al., 2013). In vitro production systems employed to generate bovine embryos, have reported that male embryos develop faster (Avery et al., 1992) and have increased blastocyst rates (Camargo et al., 2010; Ghys et al., 2016) as well as higher total cell numbers (Xu et al., 1992; 
Ghys et al., 2016; Oliveira et al., 2016) compared to female embryos. On day 7 of development, in vitro-produced female bovine blastocysts show a higher incidence of cell apoptosis than male blastocysts (Ghys et al., 2016), with the earliest detection of this effect on day 6 (Oliveira et al., 2016). Dimorphism in terms of metabolic strategy is also a distinct; this is demonstrated by the differential uptake of amino acids between male and female embryos (Sturmey et al., 2010), and was shown in a study by Green et al. (2016) in which alteration of glucose availability in culture medium induced a stronger skew in sex ratio of bovine blastocysts.

When cultured under the same conditions, embryos exhibit sexual dimorphism in up to one-third of actively expressed genes (Bermejo-Álvarez et al., 2010). Further, when exposed to adverse culture conditions, male and female conceptuses exhibit differentially altered transcriptomes (Heras et al., 2016). Additionally, mitochondrial distribution, telomere length, and DNA methylation have shown sexual dimorphism in bovine embryos (Bermejo-Álvarez et al., 2008). Though differences have been detected between male and female blastocysts, a better understanding of the role these changes play in communication to the maternal environment is warranted.

To fully understand successful pregnancy, it is important to elucidate the signaling mechanisms, or dialog, between an embryo and the mother. A potential signaling mechanism involved in regulation of embryo development is the secretion of miRNAs into the extracellular environment. miRNAs are a family of short, single-stranded, non-coding RNAs that are approximately 19-25 nucleotides in length. These small molecules modulate sequence-specific mRNA transcription, leading to regulation of gene expression (Wahid et al., 2010). Sexually divergent miRNA expression may contribute to observed differences between male and female embryos. As shown on the miRbase archive $^{1}$ (release 21; Kozomara and Griffiths-Jones, 2014), the Bos taurus Y chromosome has no known miRNAs, whereas the $\mathrm{X}$ chromosome encodes 61 known miRNAs. miRNAs can be secreted out of a cell through extracellular vesicles, via apoptotic bodies, or by being bound to AGO proteins (Turchinovich et al., 2013). In cattle, the presence of circulating miRNAs has been reported in bodily fluids such as milk (Sun et al., 2015), blood, and follicular fluid (Noferesti et al., 2015) and in the in vitro culture media of blastocysts (Kropp et al., 2014; Kropp and Khatib, 2015). miRNAs have shown involvement in a variety of biological processes including organismal development, cell proliferation, cell death, hematopoiesis, and immunity (Wahid et al., 2010). Evidence that miRNAs modulate signaling networks, such as the purinergic network - an extracellular network mediated by nucleosides such as adenosine and ATP (Ferrari et al., 2016) - supports the potential of embryo-secreted miRNAs to serve as important pathway regulators.

Embryo-secreted miRNAs have demonstrated potential to affect endometrial transcriptomes. For example, miR-30b transfected into human endometrial epithelial cells induced transcriptomic changes in the cells (Ye et al., 2015). miRNA-661

${ }^{1}$ www.miRBase.org has been shown to decrease maternal protein expression, and correlate with implantation outcome (Cuman et al., 2015). The ability of these miRNAs to alter uterine cell transcriptomes and protein expression further warrants a more comprehensive investigation of embryonic miRNAs as signaling molecules to the mother. However, it is not yet known whether miRNAs present in the culture medium of in vitro-produced embryos differ between male and female embryos. It is unknown if these miRNAs serve a function in the dialog between the embryo and the mother. We hypothesized that sexual dimorphism exists in the profiles of miRNAs secreted by blastocysts, and that these miRNAs serve as a signaling mechanism for male and female conceptuses to alter the gene expression profile in maternal endometrial cells.

\section{MATERIALS AND METHODS}

\section{Ethics Statement}

This study is exempt from approval of the institutional and national requirements of Animal Care and Use Committee because cows used for in vitro fertilization were not handled at the University of Wisconsin facilities. Ovaries used for embryo production were purchased from Applied Reproductive Technology, LLC (Monona, WI, USA), and permission was granted by the company to perform in vitro fertilization using ovaries.

\section{Experiment I: miRNA Profiling in Media In vitro Embryo and Media Production}

Embryos and media were procured as described by Kropp and Khatib (2015). Ovaries were obtained from Applied Reproductive Technology, LLC (Monona, WI, USA), and follicles were aspirated to recover oocytes. Oocytes were washed in Vigro TL-Hepes (Bioniche, Pullman, WA, USA) supplemented with $3 \%$ bovine serum albumin, sodium pyruvate, and gentamicin and placed in cohorts of 10 oocytes per $50 \mu l$ drop of maturation media for $24 \mathrm{~h}$. Maturation media consisted of M-199 media supplemented with gonadotropins (FSH and LH), estradiol, sodium pyruvate, $10 \%$ fetal bovine serum and gentamicin. Following $24 \mathrm{~h}$ of maturation, cumulus-oocyte complexes were washed in Vigro TL-Hepes (Bioniche) and transferred in cohorts of 10 into a $44 \mu \mathrm{L}$ drop of fertilization media supplemented with fatty acid-free bovine serum albumin (FAF-BSA), sodium pyruvate, and gentamicin. Sperm was prepared using a Percoll discontinuous gradient as described by Parrish et al. (1995), where the final concentration was adjusted to 1 million sperm per $\mathrm{mL}$ and $2 \mu \mathrm{L}$ was added per drop. Additionally, $2 \mu \mathrm{l}$ each of penicillamine-hypotaurineepinephrine and heparin were added to each fertilization drop.

Gametes were co-cultured with sperm for $20 \mathrm{~h}$ at which point presumptive zygotes were stripped of their cumulus cells and washed in supplemented Vigro TL-Hepes (Bioniche). The presumptive zygotes were placed 25 per drop into a $50 \mu \mathrm{L}$ drop of $\mathrm{CR}_{1 \text { aa }}$ culture media (Rosenkrans et al., 1993; Sagirkaya et al., 2006) supplemented with FAF-BSA, sodium pyruvate, 
amino acids, and gentamicin. Embryos were then cultured until day 5, whereupon they were morphologically assessed for characteristics of the morula stage as described by Bó and Mapletoft (2013). Morulae were selected based on the appearance of a coalesced/compacted inner cell mass that consumed $60-70 \%$ of the perivitelline space. Those deemed as morula stage embryos were washed and placed individually into a $50 \mu \mathrm{L}$ drop of $\mathrm{CR}_{1 \text { aa }}$ medium lacking FAF-BSA supplementation.

On day 8 of development, individually cultured embryos were morphologically assessed for characteristics of the blastocyst stage of development. Embryos which developed a blastocoel cavity and demonstrated a distinct inner cell mass and outer trophectoderm were deemed blastocysts, whereas those which failed to develop to the blastocyst stage were deemed degenerate embryos. Blastocysts that were at the mid-to-expanded blastocyst stage and quality grades 1 and 2 (Bó and Mapletoft, 2013), as well as each embryo's respective conditioned culture media, were individually collected. Blastocysts were stored in $10 \mu \mathrm{L}$ TE buffer and media was preserved in aliquots. Both embryos and media were stored at $-20^{\circ} \mathrm{C}$ for subsequent procedures. Two different sires were used for embryo generation.

\section{Sex Determination of Embryos by Nested PCR}

Individual embryos were genotyped for sex determination as described by Kirkpatrick and Monson (1993). In brief, PCR was performed using the GoTaq ${ }^{\circledR}$ DNA Polymerase system (Promega Corporation, Madison, WI, USA). Reagents [5X Green GoTaq $^{\circledR}$ Reaction Buffer, dNTPs, magnesium chloride and primers (Supplementary Table 1)], as well as proteinase $\mathrm{K}$, were added to a PCR reaction containing one blastocyst embryo in $10 \mu \mathrm{l}$ of TE buffer. To lyse each embryo, PCR reactions were incubated at the following temperatures: $50^{\circ} \mathrm{C}$ for $30 \mathrm{~min}, 95^{\circ} \mathrm{C}$ for $10 \mathrm{~min},-20^{\circ} \mathrm{C}$ for $5 \mathrm{~min}, 95^{\circ} \mathrm{C}$ for $10 \mathrm{~min}$, and $-20^{\circ} \mathrm{C}$ for $5 \mathrm{~min}$. Taq DNA polymerase was then added to each well and the first PCR was carried out with primers zfx/zfy (Aasen and Medrano, 1990; Kirkpatrick and Monson, 1993) under the following conditions: $95^{\circ} \mathrm{C}$ for $5 \mathrm{~min}$, followed by 30 cycles of $95^{\circ} \mathrm{C}$ for $60 \mathrm{~s}, 55^{\circ} \mathrm{C}$ for $45 \mathrm{~s}$, and $72^{\circ} \mathrm{C}$ for $60 \mathrm{~s}$, and a final extension step of $72^{\circ} \mathrm{C}$ for $7 \mathrm{~min}$. A nested PCR was then performed with primers specific to the $\mathrm{X}$ (zfx) and Y (zfy) chromosomes using the initial PCR product as template. The second PCR was cycled under the same conditions as the initial PCR. Embryo sex was confirmed by gel electrophoresis, where a single band was visualized for a female (X chromosome product of 246 base pairs) or two bands were visualized for a male (X chromosome band plus a Y chromosome product of 167 base pairs). A total of three IVF replicates were carried out to procure media samples derived from female and male embryos in which 102 blastocyst embryos were collected. Of the blastocysts collected, 57 blastocyst embryos were successfully genotyped, where 30 were male and 27 were female (Supplementary Table 2).

\section{RNA Extraction from Culture Media and miRNA Profiling}

For miRNA differential expression analysis between female and male embryos, a total of three pools of media were generated each for males (each pool consisted of media from 10 embryos) and females (each pool consisted of media from 9 embryos). Embryo pools were determined following IVF completion. Each pool included media from a unique set of individual embryos. Pools were designed to contain media of embryos from all three IVF runs, representing both sires equivalently across pools. RNA was extracted from each pool using a miRNeasy Serum/Plasma kit (Qiagen, Germantown, MD, USA). A total of three extractions were carried out per pool, with an initial input volume of $120-140 \mu \mathrm{L}$ media sample, consisting of an equal volume of eluent from individual embryos. miRNA profiling was performed using the Firefly ${ }^{\circledR}$ Circulating miRNA Assay Immunology Panel (ABCAM, Cambridge, MA, USA). The immunology panel includes 68 immune responserelated miRNAs chosen by ABCAM based on known functions related to immune response and differential regulation in plasma or serum. We hypothesized that these miRNAs could play a role in the immune response of the mother to the developing embryo. Complementary oligonucleotides which encode hydrogel microparticles were hybridized to selected miRNAs. The oligonucleotide adapter served as a universal PCR priming site, allowing for fluorescent amplification of the target. Amplified products were then re-hybridized to original oligonucleotide particles, and an EMD Millipore Guava 8HT Flow Cytometer (Merck, Darmstadt, Germany) was used to quantify the hybridization. Measurements were performed in triplicates.

Statistical analysis of differentially expressed miRNAs was performed using the Firefly ${ }^{\circledR}$ Analysis Workbench Software (ABCAM) in which miRNA expression levels of male and female embryos were compared to each other. An unpaired $t$-test was used to determine significant differential expression $(P<0.05)$ of miRNAs between male and female embryo groups.

\section{Validation of Differentially Expressed miRNAs Using Quantitative Real-time PCR (qRT-PCR)}

For the validation of differentially expressed miRNAs detected by Firefly ${ }^{\circledR}$ particle technology, three miRNAs (miR-22, miR-122, and miR-320a) were chosen for further analysis by qRT-PCR. A total of five additional IVF replicates were performed to generate 146 embryos derived from one sire and different dams. Fertilization, embryo grading, media collection, and embryo genotyping were performed as described above. A total of 101 blastocysts embryos were successfully genotyped for validation, resulting in 51 male and 50 female blastocysts (Supplementary Table 2). Male and female pools of media, with volumes of $40-90 \mu \mathrm{L}$, were created and RNA was extracted as described above. The three male pools were derived from 17 embryos each, while three female pools were derived from 17, 16, and 16 embryos. Total RNA was reverse-transcribed using a miScript II RT kit (Qiagen) with HiSpec Buffer following the manufacturer's instructions. The qRT-PCR method was used to determine relative fold difference in miRNA expression between male and female pools. A miR-39 spikein control (Qiagen) was added at the time of extraction 
to serve as an internal control. The miScript SYBR Green Kit (Qiagen), and specific primers (Supplementary Table 3) corresponding to each mature miRNA sequence (Qiagen) were used. Cycling conditions were carried out in a Bio-Rad iCycler real-time PCR machine as follows: $95^{\circ} \mathrm{C}$ for $15 \mathrm{~min}$ followed by 40 cycles of $94^{\circ} \mathrm{C}$ for $15 \mathrm{~s}, 55^{\circ} \mathrm{C}$ for $30 \mathrm{~s}$, and $70^{\circ} \mathrm{C}$ for $30 \mathrm{~s} . \mathrm{C}_{\mathrm{T}}$ values $>33$ were considered beyond the threshold for detection. The $2^{-\Delta \Delta \mathrm{C}_{\mathrm{T}}}$ method by Livak and Schmittgen (2001) was used to determine mean fold change in miRNA gene expression, where $\Delta \Delta \mathrm{C}_{\mathrm{T}}=\left(\mathrm{C}_{\mathrm{T}}\right.$, Target miRNA $\left.\mathrm{C}_{\mathrm{T} \text {, miR-39 }}\right)_{\text {female media }}-\left(\mathrm{C}_{\mathrm{T} \text {, Target miRNA }}-\mathrm{C}_{\mathrm{T} \text {, miR-39 }}\right)_{\text {male media }}$. The $\Delta \mathrm{C}_{\mathrm{T}}$ values were evaluated for significance using an unpaired $t$-test for each miRNA. The TargetScan software ${ }^{2}$ (Lewis et al., 2005) was used to determine candidate target genes of validated miRNAs. Each miRNA was searched by name, under both cow and human for species selection. Top predicted targets were viewed. Those which were targeted in both cow and human, and additionally had known roles in embryo development were manually identified.

\section{Experiment II: Uptake of miRNAs into Bovine Endometrial Cells \\ Primary Cell Culture of Bovine Endometrial Cells}

To investigate the potential of validated miRNAs as signaling molecules to maternal tissues, a primary cell culture system was implemented. Bovine endometrial epithelial cells (BEECs) (Cell Applications Inc., San Diego, CA, USA) were cultured for 6-8 passages and seeded in a 96-well culture plate at 7000 cells per $\mathrm{cm}^{2}$ per manufacturer instruction. Cells were cultured in Bovine Endometrial Epithelial Cell Growth Medium (Cell Applications Inc.) and passaged using Hank's Balanced Salt Solution, Trypsin/EDTA and Trypsin Inhibitor (Cell Applications Inc.), as directed.

\section{miRNA Supplementation and Collection of Primary Endometrial Epithelial Cells}

Synthetic mimics for the miRNAs miR-22, miR-122, and miR-320a (Qiagen) - specific to those found to be differentially expressed between male and female embryos - were supplemented to BEECs to assess whether these miRNAs modulate maternal gene expression. At $24 \mathrm{~h}$ post-passage of cells, $50 \mathrm{nM}$ mimic miRNA was added to a well of a 96-well plate containing BEECs. Notably, no transfection reagent was used in order to more closely simulate an in vivo setting. A control of non-treated cells was simultaneously cultured. A total of four biological replicates were produced for each miRNA mimic treatment. After $24 \mathrm{~h}$ of co-culture with the miRNA mimic, the medium was aspirated from each well, cells were washed twice in $200 \mu \mathrm{L}$ PBS, and lifted with trypsin. Cells were pelleted at $300 \mathrm{~g}$ for $5 \mathrm{~min}$, and the excess supernatant was aspirated from each tube and discarded.

To evaluate the effect of miRNAs on gene expression in the endometrial epithelial cells, an additional experiment was performed, in which cells were treated with $1 \mu \mathrm{L}$ of Lipofectamine 2000 (Thermo Fisher Scientific, Madison,

${ }^{2}$ www.targetscan.org
WI, USA) in conjunction with $50 \mathrm{nM}$ of miRNA and OptiMEM medium, as specified by the manufacturer. A control of lipofectamine-only treated cells was cultured simultaneously.

\section{Primary Endometrial Epithelial Cell miRNA and mRNA Extraction and Quantification}

Total RNA was extracted from the BEECs using a MiRNeasy Mini Kit (Qiagen) to assess miRNA uptake by the maternal cells and expression of genes targeted by supplemented miRNAs, respectively. Reverse transcription and quantification of uptake of miRNAs in cells were performed as described for media. Reverse transcription of mRNA was carried out using an iScript cDNA kit (Bio-Rad, Hercules, CA, USA) and qRT-PCR to evaluate the expression of candidate mRNA targets was performed using iTaq Universal SYBR Green Supermix (Bio-Rad). The $\beta$-actin gene was selected as an internal control according to its stability across samples in comparison to GAPDH. Intron-spanning primers were designed for each target mRNA to avoid amplification of genomic DNA (Supplementary Table 4). The CFX Connect Real-Time PCR Detection System was used for mRNA quantification with the following cycling conditions: $95^{\circ} \mathrm{C}$ for $30 \mathrm{~s}$, followed by 40 cycles of $95^{\circ} \mathrm{C}$ for $5 \mathrm{~s}$, and $60^{\circ} \mathrm{C}$ for $30 \mathrm{~s}$. Gene expression analysis was performed using the $2^{-\Delta \Delta C_{\mathrm{T}}}$ method (Livak and Schmittgen, 2001), with a control group of non-treated cells. To assess the effects of supplementation and mRNA expression changes, biological replicates were standardized as previously described (Willems et al., 2008), maximally reducing inter-sample variation between cells. Following log transformation, mean centering, and autoscaling, an unpaired $t$-test was performed to assess significance $(P<0.05)$.

\section{RESULTS}

\section{Embryo Genotyping and miRNA Profiling}

Out of 248 blastocysts collected through eight rounds of IVF, 158 embryos were successfully genotyped, resulting in a total of 81 males and 77 females. Thus, no significant sex bias was observed in our IVF system $(P>0.05)$. A total of 68 miRNAs were profiled using Firefly ${ }^{\circledR}$ technology, of which miRNAs miR-122 $(P$-value $=0.048)$, miR-16 $(P$-value $=0.042)$, miR-30b $(P$-value $=0.029), \operatorname{miR}-320 \mathrm{a}(P$-value $=0.042)$, miR$15 \mathrm{~b}(P$-value $=0.089), \operatorname{miR}-16-2(P$-value $=0.061), \mathrm{miR}-17$ $(P$-value $=0.072)$, and miR-22 $(P$-value $=0.069)$ were found to be upregulated in female-conditioned embryo media (Figure 1). A subset of miRNAs found to be differentially expressed in media of female embryos compared to male embryos (miR122, miR-22, and miR-320a) was selected for validation using qRT-PCR analysis. The qRT-PCR for miR-122, miR-22, and miR320 a was performed on three biological replicates of media for embryos produced from new dams. Expression analysis revealed upregulation of all three miRNAs in the media of females, with overall fold changes of $1.77,1.86$, and 1.86 for miR-22 $(P<0.05)$, miR-122 $(P<0.05)$, and miR-320a $(P<0.05)$, respectively (Figure 2). 

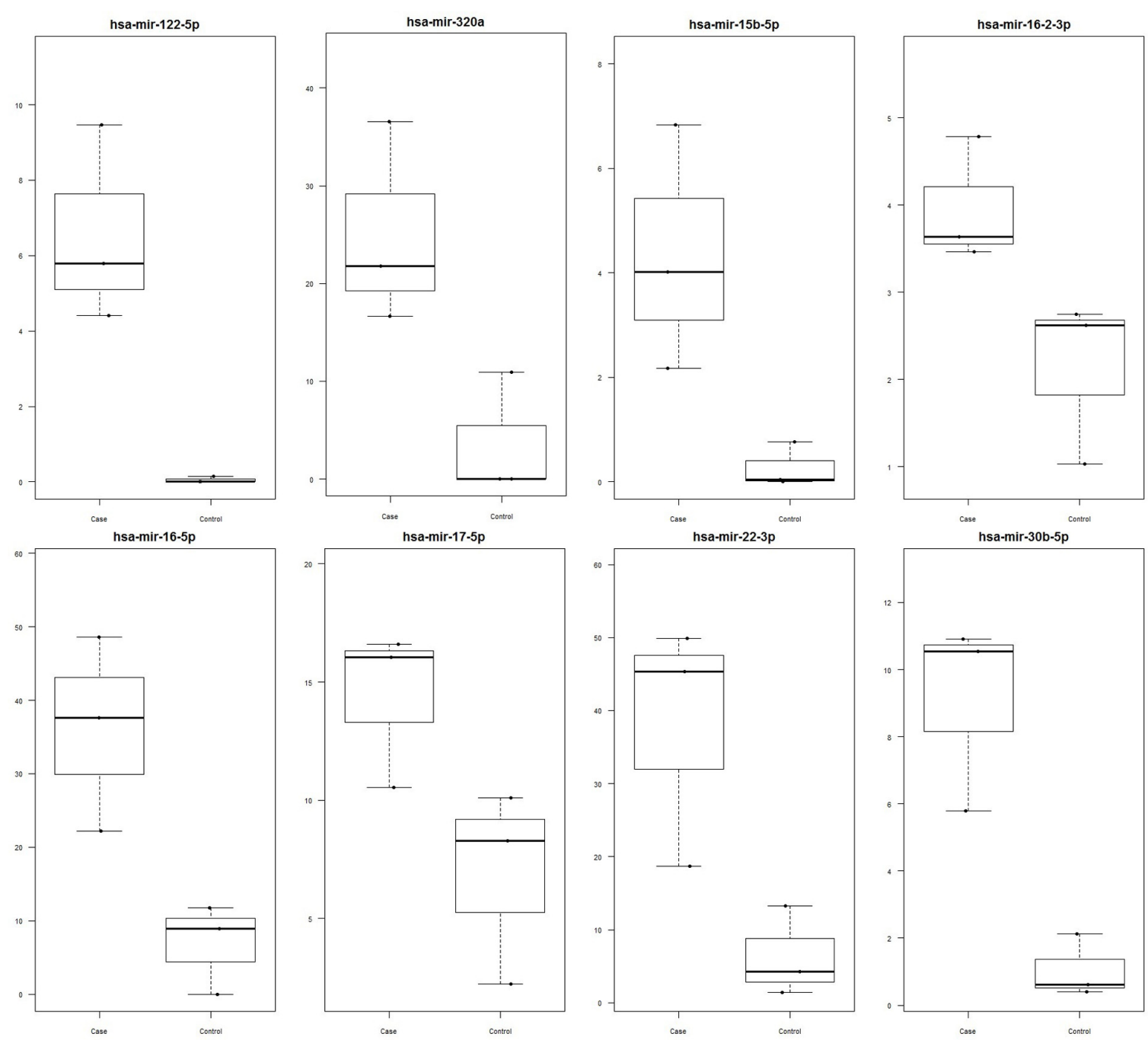

FIGURE 1 | Significantly upregulated miRNA in female versus male media as determined by Firefly ${ }^{\circledR}$ Circulating miRNA Assay Immunology Panel of 68 miRNAs (ABCAM, Cambridge, MA, USA). Data are represented as signal values for each sample. miRNAs miR-122 $(P-v a l u e=0.048)$, miR-16

$(P$-value $=0.042)$, miR-30b $(P$-value $=0.029)$, miR-320a $(P$-value $=0.042)$, miR-15b $(P$-value $=0.089)$, miR-16-2 $(P$-value $=0.061)$, miR-17 $(P$-value $=0.072)$, and miR-22 ( $P$-value $=0.069)$ were found to be significant. Female media is represented as case and male media is represented as control.

\section{miRNA Supplementation and Induction of Gene Expression Changes in Primary Cells}

To test whether embryonic miRNAs are taken up by maternal endometrial cells, synthetic miRNA mimics corresponding to miR-22, miR-122, and miR-320a were supplemented to primary endometrial epithelial cells. Figure 3 depicts the relative fold difference in expression of miRNA within BEECs following co-culture with the miRNA mimic in comparison to untreated control cells. MiR-122 $(P<0.05)$ and miR-320a $(P<0.05)$ were significantly higher in expression compared to control non-supplemented cells, with fold changes of 28.61 and 44.96, respectively. The miR-22 $(P>0.05)$ expression did not significantly differ between supplemented and control cells, though uptake was observed, with a fold change of 2.49.
To assess the impact of miRNA supplementation on gene expression changes in the BEECs, we used TargetScan ${ }^{3}$ (Lewis et al., 2005; Agarwal et al., 2015) to search for target genes of miR-22, miR-122, and miR-320a that could have important roles in fetal-mother communication. Among several candidate genes, the progesterone receptor $(P G R)$ gene was selected because it can be targeted by all three embryonic miRNAs, and is involved in the mediation of the effects of progesterone, a fundamental hormone for maintenance of pregnancy (Spencer and Bazer, 2002). Figure 4 shows the fold difference in expression of $P G R$ in endometrial cells supplemented with miRNAs miR-122, miR-22, and miR-320a compared to control cells. Interestingly, qRT-PCR analysis of a $P G R$ transcript targeted by two miRNAs revealed a significant upregulation of its expression in all four biological

\footnotetext{
${ }^{3}$ www.targetscan.org
} 


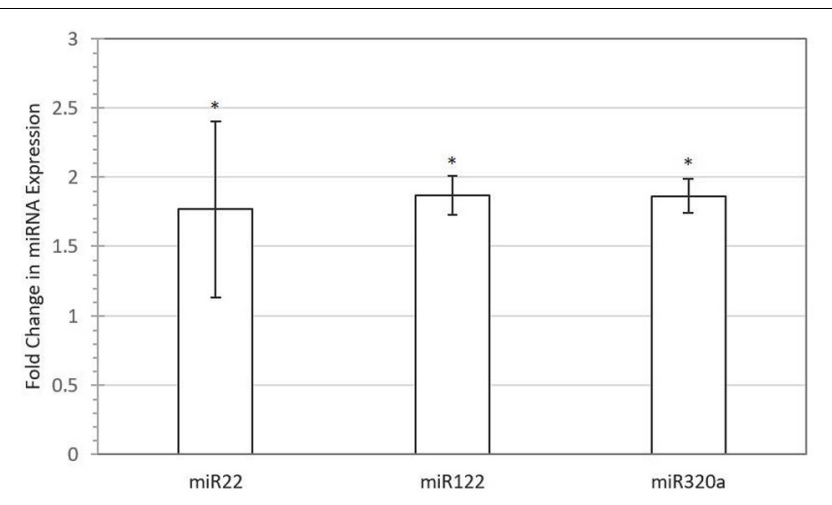

FIGURE 2 | Validation of selected miRNAs with quantitative real-time PCR (qRT-PCR). Fold difference of expression for miR-22 $(P<0.05)$, miR-122 $(P<0.05)$, and miR-320a $(P<0.05)$ in female versus male-conditioned culture medium. Error bars represent SE for the mean fold change of the expression range. Asterisk denotes significant difference between males and females.

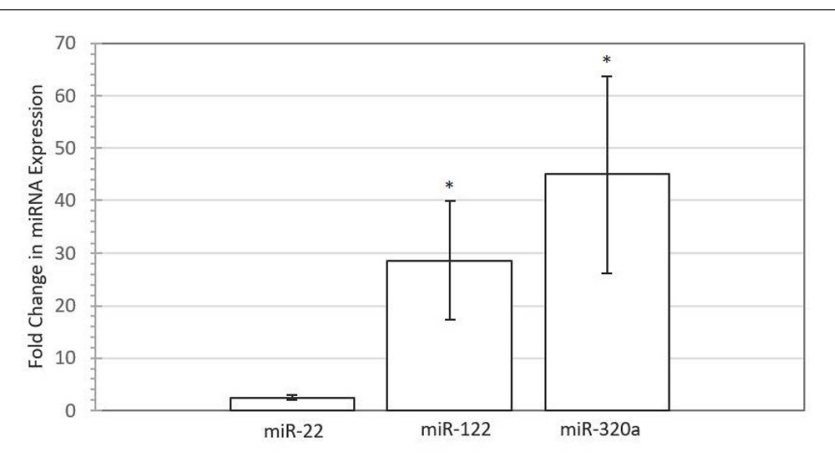

FIGURE 3 | Increased expression of miRNAs in Bovine Endometrial Epithelial Cells following supplementation with $50 \mathrm{nM}$ miRNA mimic for miR-22 ( $P>0.05)$, miR-122 $(P<0.05)$, and miR-320a $(P<0.05)$ compared with untreated control for four biological replicates. Error bars represent the SE for the mean fold change of the expression range. Asterisk denotes significant difference between treated and control cells.

replicates for each treatment, with fold changes of 2.17 and 4.18 for miR-122 $(P$-value $=0.002)$ and miR-320a $(P$-value $=0.004)$, respectively. A trend for upregulation of expression was also seen for cells treated with miR-22 $(P$-value $=0.077)$, with a fold change of 1.48. Additionally, lipofectamine-transfected cells exhibited upregulation of $P G R$ gene expression for all three miRNA treatments, with fold changes of 1.51 (miR-22), 1.50 (miR-122), and 1.41 (miR-320a) when compared with a lipofectamine-only treated control (Supplementary Table 5).

\section{DISCUSSION}

Blastocyst-secreted miRNAs may play a remarkable role in the communication of sexually dimorphic states of conceptuses to the mother. Our findings show for the first time that male and female blastocysts differentially secrete miRNAs into culture media. Furthermore, we demonstrate that these miRNAs are

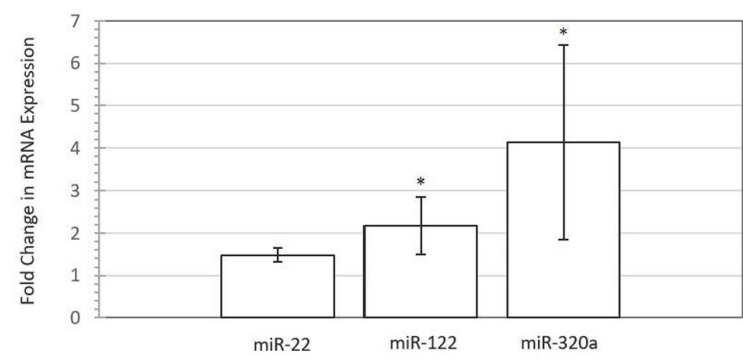

FIGURE 4 | Progesterone receptor (PGR) gene expression is increased following miRNA mimic (50 $\mathrm{nM}$ ) supplementation to bovine endometrial epithelial cells for miR-22 $(P<0.08)$, miR-122 $(P<0.05)$, and miR-320a $(P<0.05)$ compared with untreated control for four biological replicates. Error bars are represented as SE of the mean fold change for the expression range. Asterisk denotes significant difference between treated and control cells.

taken up by maternal endometrial cells. Two miRNAs targeted $P G R$ and induced upregulation of this gene, and a trend of upregulation of $P G R$ was observed for the third. The observed sexually dimorphic signaling establishes a purposeful role of miRNAs in regulating the implantation process in bovine embryos.

\section{Sexual Dimorphism of miRNA in the Culture Media of Preimplantation Embryos}

No difference in the ratio of male to female blastocysts was observed in this study, which is in agreement with other reports of in vitro-produced bovine embryos (Bermejo-Álvarez et al., 2010; Oliveira et al., 2016). Conversely, other studies have observed a higher proportion of male to female blastocysts (Camargo et al., 2010; Ghys et al., 2016). These differences in development reported across studies may reflect susceptibility of female conceptuses to environmental factors specific to the IVF system employed. For example, production of a higher proportion of male blastocysts was associated with a higher concentration of glucose in culture media (Kimura et al., 2008).

Epigenetic sexual dimorphism has previously been reported through observations of differential DNA methylation (BermejoÁlvarez et al., 2008) and gene expression (Bermejo-Álvarez et al., 2008, 2010; Forde et al., 2016). Our study is the first to show sexual dimorphism in the secretion of specific miRNAs from blastocysts into the culture medium. This finding is particularly important to understanding the mechanisms of signaling within the preimplantation stage of development, as it plausibly indicates differential physiological needs of an individual embryo that can be communicated to the dam through miRNA secretion. Moreover, differential miRNA secretion could be developed into tools that serve as a method for monitoring embryonic health.

In the present study, a total of eight miRNAs were found to be upregulated in the conditioned culture media of female embryos. Indeed, patterns observed during development indicate the secreted miRNAs upregulated in female media may serve as 
non-invasive biomarkers for embryo growth. The observation that miR-122 decreases from hours 0 to 22 of maturation in bovine oocytes (Abd El Naby et al., 2016) and the detection of miR-320a in human embryo culture medium at the cleavage, morula, and blastocyst stages (Capalbo et al., 2016) indicate these miRNAs could serve as continuous markers of embryo developmental checkpoints. A study by Feng et al. (2015) identified that presence of miR-320 in the human follicular fluid is decreased in patients using intracytoplasmic sperm injection to conceive, and knockdown of miR-320 in mouse oocytes negatively affects developmental potential of embryos through inhibition of the Wnt signaling pathway. Additionally, miR22 functions in human cells during apoptosis - a process which is known to be differentially regulated between male and female blastocysts (Ghys et al., 2016; Oliveira et al., 2016), suppressing tumor growth through inhibition of ATP citrate lyase (Xin et al., 2016). Further, miR-22 has been observed in media of bovine embryos which degenerate prematurely, failing to successfully form blastocysts (Kropp and Khatib, 2015). Both miR-30b (Ye et al., 2015) and miR-15 (Zhang et al., 2015) are involved in regulation of the epithelial-mesenchymal transition in cancer cells, which bears many similarities to the epithelial-mesenchymal transition important for successful implantation and gastrulation (Kalluri and Weinberg, 2009). miR-16 has been shown to inhibit angiogenesis, through targeting of vascular endothelial growth factor, serving as a potential cause of recurrent spontaneous abortions (Zhu et al., 2016). Taken together, the miRNAs found in this study may serve as noninvasive markers for the differential needs of male and female embryos.

\section{miRNAs as Signaling Molecules for Early Development}

Significant uptake of miR-122 and miR-320a, as well as a trend of uptake for miR-22, were observed in this study. Internalization of miRNAs by endometrial cells exhibits the ability for these molecules to interact with the maternal environment and indicates their potential to function as signaling molecules. This study showed endometrial cell uptake of miRNA at half the concentration used previously by Cuman et al. (2015) on human endometrial cells, and without need of a transfection reagent. Lipofectamine 2000 was used in this study to show miRNAs (with aided transport into cells) can affect expression of PGR. Indeed, internalization of miRNAs, as well as increase in $P G R$ was observed compared with the lipofectamine-only control.

Mechanisms through which endometrial cells take up various miRNAs have yet to be demonstrated, though the uptake of two out of three distinct miRNAs indicates passage of miRNAs into cells may be somewhat selective. It is unknown whether endometrial cells perform uptake through various modes, given that transport of extracellular miRNAs can occur through binding of the miRNA to the AGO protein, apoptotic bodies, or extracellular vesicles (microvesicles and exosomes) (Turchinovich et al., 2013). Successful transport of miRNAs could impact developmental success of the early embryo, and should thus be further interrogated.
Interestingly, the miRNAs investigated in this study have been shown to affect processes critical to the establishment of an interface between the embryo and the mother. Angiogenesis, a process necessary for embryo viability, is inhibited by miR320 in rat myocardial microvascular endothelial cells (Wang et al., 2009). Normal rat ovarian function is linked to the roles of miR-122, which stimulates activation of the sterol response binding protein pathway, leading to $\mathrm{LH}$ receptor downregulation (Menon et al., 2015). The estrogen receptor ER $\alpha$ was shown to be downregulated by transfection with miR-22 in endometrioid carcinomas, where continuous stimulation by estrogen is considered a risk factor for tumorigenesis ( $\mathrm{Li}$ and Yang, 2013). Thus, miRNAs found in our study have the potential to regulate cell function in the mother.

\section{Involvement of Progesterone Receptor in Conceptus-to-Mother Communication}

Computational prediction revealed that all three miRNAs (miR-22, miR-122, and miR-320a) collectively target PGR, and further functional analysis showed a trend of upregulation of the $P G R$ transcript following supplementation with these miRNAs individually. Interestingly, upregulation of $P G R$ was correlated with the level of uptake of each miRNA into endometrial cells (Figures 3, 4). Most reported mechanisms for miRNA targeting of transcripts involve degradation of the transcript or inhibition of translation (Wahid et al., 2010). However, upregulation of transcripts by miRNAs has been described to occur through direct and indirect mechanisms, as well as in relation to cell state and transcript composition (Rusk, 2008; Vasudevan, 2012; Orang et al., 2014). Particularly, miR-122 has shown the ability to upregulate a transcript for hepatitis $\mathrm{C}$ virus by providing a scaffold for binding of essential factors to transcription, such as RNA polymerase, and enhancing binding of the 40s ribosomal subunit (Orang et al., 2014). Additional modes of upregulation include stabilization of the 5 ' end of transcripts, cell cycle state-specific regulation, and protection of AU-rich regions of transcripts (Rusk, 2008; Vasudevan, 2012; Orang et al., 2014), as well as various undefined mechanisms. In the present study, the exact mechanism through which this upregulation of $P G R$ occurs was not investigated. Future studies should expand on understanding the modes of upregulation which could lead to these effects on PGR.

Further, the substantial upregulation of the $P G R$ transcript by all three miRNAs demonstrates a complex collective targeting network of miRNAs working toward regulation of a common gene. TargetScan ${ }^{4}$ (Lewis et al., 2005; Agarwal et al., 2015) analysis of targeting sites (data not shown) indicates all three miRNAs could bind to separate regions of the PGR $3^{\prime}$ UTR, demonstrating the possibility that several miRNAs could also simultaneously induce effects on the PGR transcript. This gives cause for future investigation of the potential networks conceptus-produced miRNAs may form. Interpreting these interactions may better elucidate signaling mechanisms between the conceptus and mother during preimplantation development.

\footnotetext{
${ }^{4}$ www.targetscan.org
} 
The most well-studied aspect of $P G R$ is its interaction with progesterone, a hormone essential to the maintenance of pregnancy and thus, upregulation of $P G R$ expression could have implications for the understanding of mechanisms of cow fertility prior to and during implantation. Establishment of uterine receptivity to the conceptus has been shown to require a loss of $P G R$ expression in the luminal epithelium and then later from the glandular epithelium as a result of elevated progesterone (Bazer et al., 2009). Progesterone presence in the endometrium is involved in stimulation of blastocyst growth and elongation as well as upregulation of a number of genes critical for adhesion as well as amino acid transport (Spencer et al., 2007). Studies evaluating artificial supplementation of progesterone have demonstrated an association of its administration with induction of gene expression profiles in the endometrium which are similar to expression profiles of normal endometrium interacting with more advanced conceptuses later in normal development (Forde et al., 2009). Embryos do not necessarily need to be present in the uterus at times of elevated progesterone in order to benefit from its effects (Clemente et al., 2009; O'Hara et al., 2014) and artificial elevation of progesterone early in the estrous cycle has been seen to cause decreased size of the corpus luteum, which could induce luteolysis and lead to early embryo loss (O'Hara et al., 2014). Therefore, it is possible that miRNA secretion may serve as a way for embryos to maintain a local level of control over $P G R$ in order to mediate effects of progesterone on the endometrium. Although cyclic and non-cyclic cows show little divergence in endometrial transcriptomes until day 16, termed the recognition point of bovine pregnancy (Forde et al., 2011), local effects at early stages of development remain a challenge to measure and may still exist. It is unknown whether the upregulation of $P G R$ in the endometrium during the preimplantation period is favorable for successful embryo development and implantation.

Our study was based on in vitro investigation of pooled media of blastocysts. In vivo models have not been employed to evaluate preimplantation embryo-secreted miRNAs. This is due partially to the challenge of developing precise techniques to measure expression changes induced by embryos within maternal tissues. For example, one study determined that transcriptomic changes occur in the epithelial cells in the oviduct as a result of embryo transfer, but individual embryo influences on the cells were undetectable and were only found to occur with the transfer of 50 embryos (Maillo et al., 2015). Further investigation of these secreted miRNAs should also lead to a better understanding of the differences between individual blastocysts in order to uncover the biology behind this secretion and to develop ways to monitor individual conceptuses throughout development.

Although this study was limited to a panel of miRNAs chosen specifically for their impacts on immunity as opposed to a high-throughput sequencing approach, the results provide a basis for identifying larger-scale dimorphisms of secreted miRNAs. A comprehensive understanding of the exact roles for sexually dimorphic miRNA production has not yet been attained, but future research should focus on understanding larger-scale interactions and collective targeting of subsets of miRNAs on mRNA transcripts in order to better elucidate the roles these molecules may play in maternal cells and to accommodate optimal development of blastocysts relative to their sex.

\section{CONCLUSION}

The current study demonstrates the potential for blastocysts of differing sex to produce dimorphic signals in the form of miRNAs, which can collectively impose changes in transcripts of maternal cells. Endometrial cell internalization of miRNAs, and subsequent upregulation of $P G R$ is a remarkable display of the potential for miRNAs to function as signaling molecules during preimplantation development and allows for a new perspective on understanding the preparation of maternal cells for interaction with blastocysts, which already contain inherent differences due to their sex. Male and female embryo dimorphism in miRNA production allows for future discovery of invaluable biomarkers of embryo signaling, and understanding the potential roles of miRNAs in preimplantation development blastocyst-tomother communication.

\section{AUTHOR CONTRIBUTIONS}

NG carried out the experiments, data analysis and drafting of the manuscript. JK participated in the in vitro production of embryos and editing the manuscript. HK conceived the study and participated in the design of experiments and drafting of the manuscript.

\section{FUNDING}

This work was supported by USDA Formula Funds (MSN168911).

\section{ACKNOWLEDGMENTS}

The authors would like to thank John Parrish and Rick Monson for guidance in the production of embryos.

\section{SUPPLEMENTARY MATERIAL}

The Supplementary Material for this article can be found online at: http://journal.frontiersin.org/article/10.3389/fgene. 2017.00039/full\#supplementary-material 


\section{REFERENCES}

Aasen, E., and Medrano, J. (1990). Amplification of the ZFY and ZFX genes for sex identification in humans, cattle, sheep and goats. Biotechnology 8, 1279-1281.

Abd El Naby, W. S., Hagos, T. H., Hossain, M. M., Gad, A. Y., Rings, F., Cinar, M. U., et al. (2016). Expression analysis of regulatory microRNAs in bovine cumulus oocyte complex and preimplantation embryos. Zygote 21, 31-51. doi: $10.1017 /$ S0967199411000566

Agarwal, V., Bell, G. W., Nam, J. W., and Bartel, D. P. (2015). Predicting effective microRNA target sites in mammalian mRNAs. Elife 4, 1-38. doi: 10.7554/eLife. 05005

Avery, B., Jorgensen, C. B., Madison, V., and Greve, T. (1992). Morphological development and sex of bovine in vitro fertilized embryos. Mol. Reprod. Develop. 32, 265-270.

Bazer, F. W., Wu, G., Spencer, T. E., Johnson, G. A., Burghardt, R. C., and Bayless, K. (2009). Novel pathways for implantation and establishment and maintenance of pregnancy in mammals. Mol. Hum. Reprod. 16, 135-152. doi: 10.1093/molehr/gap095

Bermejo-Álvarez, P., Rizos, D., Rath, D., Lonergan, P., and GutierrezAdan, A. (2008). Epigenetic differences between male and female bovine blastocysts produced in vitro. Physiol. Genomics 32, 264-272. doi: 10.1152/ physiolgenomics.00234.2007

Bermejo-Álvarez, P., Rizos, D., Rath, D., Lonergan, P., and Gutierrez-Adan, A. (2010). Sex determines the expression level of one third of the actively expressed genes in bovine blastocysts. Proc. Natl. Acad. Sci. U.S.A. 107, 3394-3399. doi: 10.1073/pnas.0913843107

Bó, G. A., and Mapletoft, R. J. (2013). Evaluation and classification of bovine embryos. Anim. Reprod. 10, 344-348.

Camargo, L. S. A., Freitas, C., de Sa, W. F., de Moraes Ferreira, A., Serapiao, R. V., and Viana, J. H. M. (2010). Gestation length, birth weight and offspring gender ratio of in vitro-produced Gyr (Bos indicus) cattle embryos. Anim. Reprod. Sci. 120, 10-15. doi: 10.1016/j.anireprosci.2010.02.013

Capalbo, A., Ubaldi, F. M., Cimadomo, D., Noli, L., Khalaf, Y., Farcomeni, A., et al. (2016). MicroRNAs in spent blastocyst culture medium are derived from trophectoderm cells and can be explored for human embryo reproductive competence assessment. Fertil. Steril. 105, 225.e1-3-235.e1-3. doi: 10.1016/j. fertnstert.2015.09.014

Clemente, M., De La Fuente, J., Fair, T., Al Naib, A., Gutierrez-Adan, A., Roche, J. F., et al. (2009). Progesterone and conceptus elongation in cattle: a direct effect on the embryo or an indirect effect via the endometrium? Reproduction 138, 507-517. doi: 10.1530/REP-09-0152

Cuman, C., Van Sinderen, M., Gantier, M. P., Rainczuk, K., Sorby, K., Rombauts, L., et al. (2015). Human blastocyst secreted microRNA regulate endometrial epithelial cell adhesion. EBioMedicine 2, 1528-1535. doi: 10.1016/j.ebiom.2015. 09.003

Feng, R., Sang, Q., Zhu, Y., Fu, W., Liu, M., Xu, Y., et al. (2015). MiRNA-320 in the human follicular fluid is associated with embryo quality in vivo and affects mouse embryonic development in vitro. Sci. Rep. 5:8689. doi: 10.1038/ srep08689

Ferrari, D., Bianchi, N., Eltzschig, H. K., and Gambari, R. (2016). MicroRNAs modulate the purinergic signaling network. Trends Mol. Med. 22, 905-918. doi: 10.1016/j.molmed.2016.08.006

Forde, N., Carter, F., Fair, T., Crowe, M. A., Evans, A. C. O., Spencer, T. E., et al. (2009). Progesterone-regulated changes in endometrial gene expression contribute to advanced conceptus development in cattle. Biol. Reprod. 81, 784-794. doi: 10.1095/biolreprod.108.074336

Forde, N., Carter, F., Spencer, T. E., Bazer, F. W., Sandra, O., Mansouri-Attia, N., et al. (2011). Conceptus-induced changes in the endometrial transcriptome: How soon does the cow know she is pregnant? Biol. Reprod. 85, 144-156. doi: 10.1095/biolreprod.110.090019

Forde, N., Maillo, V., O'Gaora, P., Simintiras, C. A., Sturmey, R. G., Ealy, A. D., et al. (2016). Sexually dimorphic gene expression in bovine conceptuses at the initiation of implantation. Biol. Reprod. 95, 92. doi: 10.1095/biolreprod.116. 139857

Ghys, E., Dallemagne, M., De Troy, D., Sauvegarde, C., Errachid, A., and Donnay, I. (2016). Female bovine blastocysts are more prone to apoptosis than male ones. Theriogenology 85, 591-600. doi: 10.1016/j.theriogenology.2015. 09.050
Green, M. P., Harvey, A. J., Spate, L. D., Kimura, K., Thompson, J. G., and Roberts, R. M. (2016). The effects of 2,4-dinitrophenol and d-glucose concentration on the development, sex ratio, and interferon-tau (IFNT) production of bovine blastocysts. Mol. Reprod. Dev. 83, 50-60. doi: 10.1002/mrd.22590

Heras, S., De Coninck, D. I. M., van Poucke, M., Goossens, K., Bogado Pascottini, O., Van Nieuwerburgh, F., et al. (2016). Suboptimal culture conditions induce more deviations in gene expression in male than female bovine blastocysts. BMC Genomics 17, 72. doi: 10.1186/s12864-016-2393-z

Kalluri, R., and Weinberg, R. A. (2009). Review series: the basics of epithelialmesenchymal transition. J. Clin. Invest. 119, 1420-1428. doi: 10.1172/JCI39104. 1420

Kimura, K., Iwata, H., and Thompson, J. G. (2008). The effect of glucosamine concentration on the development and sex ratio of bovine embryos. Anim. Reprod. Sci. 103, 228-238. doi: 10.1016/j.anireprosci.2006.12.014

Kirkpatrick, B. W., and Monson, R. L. (1993). Sensitive sex determination assay applicable to bovine embryos derived from IVM and IVF. J. Reprod. Fertil. 98, 335-340. doi: 10.1530/jrf.0.0980335

Kozomara, A., and Griffiths-Jones, S. (2014). MiRBase: annotating high confidence microRNAs using deep sequencing data. Nucleic Acids Res. 42, 68-73. doi: 10.1093/nar/gkt1181

Kropp, J., and Khatib, H. (2015). Characterization of microRNA in bovine in vitro culture media associated with embryo quality and development. J. Dairy Sci. 98, 6552-6563. doi: 10.3168/jds.2015-9510

Kropp, J., Salih, S. M., and Khatib, H. (2014). Expression of microRNAs in bovine and human pre-implantation embryo culture media. Front. Genet. 5:91. doi: 10.3389/fgene.2014.00091

Laguna-Barraza, R., Bermejo-Álvarez, P., Ramos-Ibeas, P., De Frutos, C., LópezCardona, A. P., Calle, A., et al. (2013). Sex-specific embryonic origin of postnatal phenotypic variability. Reprod. Fertil. Dev. 25, 38-47. doi: 10.1071/ RD12262

Lewis, B. P., Burge, C. B., and Bartel, D. P. (2005). Conserved seed pairing, often flanked by adenosines, indicates that thousands of human genes are microRNA targets. Cell 120, 15-20. doi: 10.1016/j.cell.2004.12.035

Li, H., and Yang, B. B. (2013). Friend or foe: the role of microRNA in chemotherapy resistance. Acta Pharmacol. Sin. 34, 870-879. doi: 10.1038/aps.2013.35

Livak, K. J., and Schmittgen, T. D. (2001). Analysis of relative gene expression data using real-time quantitative PCR and. Methods 25, 402-408. doi: 10.1006/meth. 2001.1262

Maillo, V., Gaora, P. O., Forde, N., Besenfelder, U., Havlicek, V., Burns, G. W., et al. (2015). Oviduct-embryo interactions in cattle: two-way traffic or a one-way street? Biol. Reprod. 92, 144-144. doi: 10.1095/biolreprod.115.127969

Menon, B., Gulappa, T., and Menon, K. M. J. (2015). MIR-122 regulates LH receptor expression by activating sterol response element binding protein in rat ovaries. Endocrinology 156, 3370-3380. doi: 10.1210/en.2015-1121

Noferesti, S. S., Sohel, M. M. H., Hoelker, M., Salilew-Wondim, D., Tholen, E., Looft, C., et al. (2015). Controlled ovarian hyperstimulation induced changes in the expression of circulatory miRNA in bovine follicular fluid and blood plasma. J. Ovarian Res. 8, 81. doi: 10.1186/s13048-015-0208-5

O'Hara, L., Forde, N., Carter, F., Rizos, D., Maillo, V., Ealy, A. D., et al. (2014). Paradoxical effect of supplementary progesterone between day 3 and day 7 on corpus luteum function and conceptus development in cattle. Reprod. Fertil. Dev. 26, 328-336. doi: 10.1071/RD12370

Oliveira, C. S., Saraiva, N. Z., de Lima, M. R., Oliveira, L. Z., Serapião, R. V., Garcia, J. M., et al. (2016). Cell death is involved in sexual dimorphism during preimplantation development. Mech. Dev. 139, 42-50. doi: 10.1016/j.mod.2015. 12.001

Orang, A. V., Safaralizadeh, R., and Kazemzadeh-Bavili, M. (2014). Mechanisms of miRNA-mediated gene regulation from common downregulation to mRNAspecific upregulation. Int. J. Genomics 2014:970607. doi: 10.1155/2014/970607

Parrish, J. J., Krogenaes, A., and Susko-Parrish, J. L. (1995). Effect of bovine sperm separation by either swim-up or Percoll method on success of in vitro fertilization and early embryonic development. Theriogenology 44, 859-869. doi: 10.1016/0093-691X(95)00271-9

Rosenkrans, C. F., Zeng, G. Q., MCNamara, G. T., Schoff, P. K., and First, N. L. (1993). Development of bovine embryos in vitro as affected by energy substrates. Biol. Reprod. 49, 459-462. doi: 10.1095/biolreprod49.3.459

Rusk, N. (2008). When microRNAs activate translation. Nat. Methods 5, 122-123. doi: $10.1038 /$ nmeth0208-122a 
Sagirkaya, H., Misirlioglu, M., Kaya, A., First, N. L., Parrish, J. J., and Memili, E. (2006). Developmental and molecular correlates of bovine preimplantation embryos. Reproduction 131, 895-904. doi: 10.1530/rep.1.01021

Spencer, T. E., and Bazer, F. W. (2002). Biology of progesterone action during pregnancy recognition and maintenance of pregnancy. Front. Biosci. 7, d1879-d1898.

Spencer, T. E., Johnson, G. A., Bazer, F. W., Burghardt, R. C., and Palmarini, M. (2007). Pregnancy recognition and conceptus implantation in domestic ruminants: roles of progesterone, interferons and endogenous retroviruses. Reprod. Fertil. Dev. 19, 65-78. doi: 10.1071/ RD06102

Sturmey, R. G., Bermejo-Álvarez, P., Gutierrez-Adan, A., Rizos, D., Leese, H. J., and Lonergan, P. (2010). Amino acid metabolism of bovine blastocysts: a biomarker of sex and viability. Mol. Reprod. Dev. 77, 285-296. doi: 10.1002/mrd. 21145

Sun, J., Aswath, K., Schroeder, S. G., Lippolis, J. D., Reinhardt, T. A., and Sonstegard, T. S. (2015). MicroRNA expression profiles of bovine milk exosomes in response to Staphylococcus aureus infection. BMC Genomics 16, 806. doi: 10.1186/s12864-015-2044-9

Turchinovich, A., Samatov, T. R., Tonevitsky, A. G., and Burwinkel, B. (2013). Circulating miRNAs: cell-cell communication function? Front. Genet. 4:119. doi: 10.3389/fgene.2013.00119

Vasudevan, S. (2012). Posttranscriptional upregulation by microRNAs. Wiley Interdiscip. Rev. RNA 3, 311-330. doi: 10.1002/wrna.121

Wahid, F., Shehzad, A., Khan, T., and Kim, Y. Y. (2010). MicroRNAs: synthesis, mechanism, function, and recent clinical trials. Biochim. Biophys. Acta 1803, 1231-1243. doi: 10.1016/j.bbamcr.2010.06.013

Wang, X. H., Qian, R. Z., Zhang, W., Chen, S. F., Jin, H. M., and Hu, R. M. (2009). MicroRNA-320 expression in myocardial microvascular endothelial cells and its relationship with insulin-like growth factor- 1 in type 2 diabetic rats. Clin. Exp. Pharmacol. Physiol. 36, 181-188. doi: 10.1111/j.1440-1681.2008. 05057.x
Willems, E., Leyns, L., and Vandesompele, J. (2008). Standardization of realtime PCR gene expression data from independent biological replicates. Anal. Biochem. 379, 127-129. doi: 10.1016/j.ab.2008.04.036

Xin, M., Qiao, Z., Li, J., Liu, J., Song, S., Zhao, X., et al. (2016). miR-22 inhibits tumor growth and metastasis by targeting ATP citrate lyase: evidence in osteosarcoma, prostate cancer, cervical cancer and lung cancer. Oncotarget 7, 44252-44265. doi: 10.18632/oncotarget.10020

Xu, K. P., Yadav, B. R., King, W. A., and Betteridge, K. J. (1992). Sex-related differences in developmental rates of bovine embryos produced and cultured in vitro. Mol. Reprod. Dev. 31, 249-252. doi: 10.1002/mrd.1080310404

Ye, Z., Zhao, L., Li, J., Chen, W., and Li, X. (2015). miR-30d blocked transforming growth factor betal-induced epithelial-mesenchymal transition by targeting snail in ovarian cancer cells. Int. J. Gynecol. Cancer 25, 1574-1581. doi: 10.1097/ IGC.0000000000000546

Zhang, W. L., Zhang, J. H., Wu, X. Z., Yan, T., and Lv, W. (2015). miR-15b promotes epithelial-mesenchymal transition by inhibiting SMURF2 in pancreatic cancer. Int. J. Oncol. 47, 1043-1053. doi: 10.3892/ijo.2015.3076

Zhu, Y., Lu, H., Huo, Z., Ma, Z., Dang, J., Dang, W., et al. (2016). MicroRNA-16 inhibits feto-maternal angiogenesis and causes recurrent spontaneous abortion by targeting vascular endothelial growth factor. Sci. Rep. 6:35536. doi: 10.1038/ srep35536

Conflict of Interest Statement: The authors declare that the research was conducted in the absence of any commercial or financial relationships that could be construed as a potential conflict of interest.

Copyright (c) 2017 Gross, Kropp and Khatib. This is an open-access article distributed under the terms of the Creative Commons Attribution License (CC BY). The use, distribution or reproduction in other forums is permitted, provided the original author(s) or licensor are credited and that the original publication in this journal is cited, in accordance with accepted academic practice. No use, distribution or reproduction is permitted which does not comply with these terms. 